\title{
Lower Extremity Biomechanics and Self-Reported Foot-Strike Patterns Among Runners in Traditional and Minimalist Shoes
}

\author{
Donald L. Goss, PhD, PT, OCS, ATC*; Michael Lewek, PhD, PT†; \\ Bing Yu, PhD†; William B. Ware, PhD†; Deydre S. Teyhen, PhD, PT, OCSł; \\ Michael T. Gross, PhD, PT†
}

*US Military-Baylor University Sports Medicine Doctoral Program, Keller Army Community Hospital, West Point, NY; †University of North Carolina at Chapel Hill; $¥$ System for Health and Performance Triad, Defense Health Headquarters, Falls Church, VA

Context: The injury incidence rate among runners is approximately $50 \%$. Some individuals have advocated using an anterior-foot-strike pattern to reduce ground reaction forces and injury rates that they attribute to a rear-foot-strike pattern. The proportion of minimalist shoe wearers who adopt an anterior-foot-strike pattern remains unclear.

Objective: To evaluate the accuracy of self-reported footstrike patterns, compare negative ankle- and knee-joint angular work among runners using different foot-strike patterns and wearing traditional or minimalist shoes, and describe average vertical-loading rates.

Design: Descriptive laboratory study.

Setting: Research laboratory.

Patients or Other Participants: A total of 60 healthy volunteers ( 37 men, 23 women; age $=34.9 \pm 8.9$ years, height $=1.74 \pm 0.08 \mathrm{~m}$, mass $=70.9 \pm 13.4 \mathrm{~kg}$ ) with more than 6 months of experience wearing traditional or minimalist shoes were instructed to classify their foot-strike patterns.

Intervention(s): Participants ran in their preferred shoes on an instrumented treadmill with 3-dimensional motion capture.

Main Outcome Measure(s): Self-reported foot-strike patterns were compared with 2-dimensional video assessments.
Runners were classified into 3 groups based on video assessment: traditional-shoe rear-foot strikers (TSR; $n=22$ ), minimalist-shoe anterior-foot strikers (MSA; $n=21$ ), and minimalist-shoe rear-foot strikers (MSR; $n=17$ ). Ankle and knee negative angular work and average vertical-loading rates during stance phase were compared among groups.

Results: Only 41 (68.3\%) runners reported foot-strike patterns that agreed with the video assessment $(\kappa=0.42, P<$ $.001)$. The TSR runners demonstrated greater ankle-dorsiflexion and knee-extension negative work than MSA and MSR runners $(P<.05)$. The MSA $(P<.001)$ and MSR $(P=.01)$ runners demonstrated greater ankle plantar-flexion negative work than TSR runners. The MSR runners demonstrated a greater average vertical-loading rate than MSA and TSR runners $(P<$ .001).

Conclusions: Runners often cannot report their foot-strike patterns accurately and may not automatically adopt an anterior-foot-strike pattern after transitioning to minimalist running shoes.

Key Words: barefoot running, ground reaction forces, negative work, loading rate

\section{Key Points}

- Accuracy of self-reported foot-strike patterns for runners wearing minimalist running shoes was poor.

- A cohort of runners who wore minimalist shoes for at least 6 months demonstrated a rear-foot-strike pattern and potentially injurious ground reaction force rates of loading.

- Runners using a rear-foot-strike pattern and wearing traditional shoes demonstrated more overall knee excursion, greater knee-extension negative work, and greater ankle-dorsiflexion negative work than runners wearing minimalist shoes, regardless of foot-strike pattern.

$\mathrm{M}$ ore than 19 million individuals run for exercise in the United States. ${ }^{1}$ Annually, the incidence of overuse running injuries averages $50 \%$, with nearly half of those injuries occurring at the knee., ${ }^{2,3}$ Greater vertical ground reaction force loading rates and vertical impact peak recently have been associated with increased injury risk in runners with a history of tibial stress fractures, ${ }^{4}$ patellofemoral pain, ${ }^{5}$ and plantar fasciitis. ${ }^{6}$ Greater braking forces also have been associated with tibial stress fracture. ${ }^{7,8}$
Several biomechanical researchers ${ }^{9-12}$ have observed that most runners demonstrate a rear-foot-strike pattern. Rearfoot-strike running, with the heel making initial contact with the ground, has been associated with greater knee-joint loading $^{13}$ and greater initial vertical-loading rates than running with a more anterior-foot-strike pattern. ${ }^{9}$ Running with an increased stride frequency may reduce knee-joint loading. ${ }^{14}$ Greater knee-joint loading, measured in greater negative work for the knee extensors, may contribute to the increased incidence of knee-joint injuries among runners. 


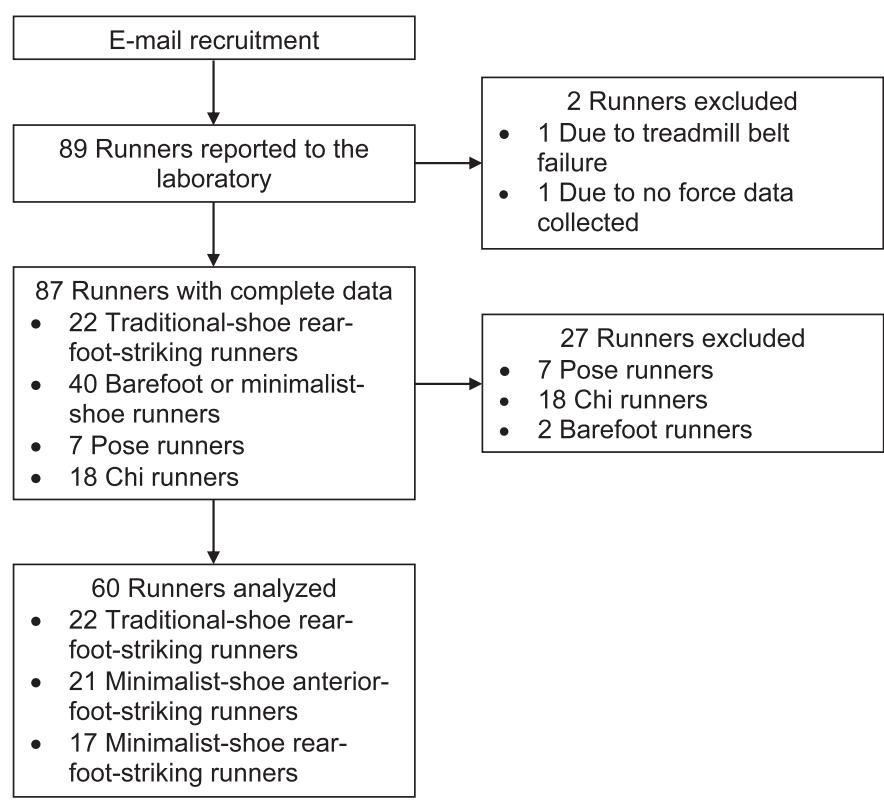

Figure 1. Schematic diagram that details group recruitment and composition.

Using a more anterior-foot-strike pattern in traditional or minimalist footwear may result in less knee-joint loading and possibly more ankle-joint loading with potentially fewer knee-joint overuse injuries, with or without an increase in ankle and foot overuse injuries. We propose that angular work at the knee and ankle joints is a variable that may indicate stress imposed on soft tissues (eg, muscletendon forces), as well as articular contact forces at these joints.

Whereas habitual barefoot running has been characterized by more anterior initial foot contact, ${ }^{9,15-17}$ shorter stride lengths, and greater stride frequency, ${ }^{18,19}$ Hatala et $\mathrm{al}^{12}$ recently reported on a cohort of habitual barefoot runners who demonstrated a rear-foot-strike pattern. Some runners who wear minimalist running shoes have demonstrated mechanics similar to those of barefoot runners. ${ }^{17}$ However, the assumption that all runners who wear minimalist shoes will use an anterior-foot-strike pattern may not be accurate. McCarthy et $\mathrm{al}^{20}$ observed that $50 \%$ of runners continued to demonstrate a rear-foot-strike pattern 2 weeks after transitioning to minimalist running shoes. Many runners may believe they have adopted a more anterior-foot-strike pattern when they are still heel striking. Continuing to use a rear-foot-strike pattern after transitioning to minimalist footwear or running in bare feet may lead to potentially injurious vertical ground reaction force rates of loading. To our knowledge, no researchers have investigated the accuracy of self-reported foot-strike patterns of runners who habitually wore traditional or minimalist shoes for at least 6 months. We also are unaware of any comparisons of joint loading (measured in angular work) between runners in traditional and minimalist footwear with different foot-strike patterns. Therefore, the purposes of our study were (1) to evaluate the accuracy of self-reported foot-strike patterns between runners wearing traditional and minimalist running shoes, (2) to compare negative ankle- and knee-joint work among running groups, and (3) to compare average vertical loading rates (AVLR; ie, the slope of the impact phase of the vertical ground reaction force curve) among groups of runners using different foot-strike patterns and shoe types. Although we were unsure of the accuracy of self-reported foot-strike patterns, we hypothesized that they would not be different between runners who wore traditional running shoes and runners who wore minimalist shoes. We expected that runners who used an anterior-foot-strike pattern would demonstrate less negative work at the knee joint and more negative ankle plantar-flexion work than runners who used a rear-foot-strike pattern. We also hypothesized that runners using a rear-foot-strike pattern would demonstrate greater AVLR than runners using an anterior-foot-strike pattern, irrespective of shoe type. We also compared groups for running speed, knee and ankle excursion, step frequency, and maximal vertical ground reaction force to clarify our interpretation of the results for the primary study variables.

\section{METHODS}

\section{Participants}

A total of 89 runners volunteered for the study (Figure 1). To be considered runners, volunteers had to run a minimum of 12 miles $(19.2 \mathrm{~km})$ per week. We excluded 2 runners who had incomplete data collection, 2 runners who ran in bare feet, and 25 runners who specifically stated they had an anterior-foot-strike pattern but were trained formally in the Chi or Pose running style. Chi and Pose running styles require multiple adaptations to running form outside of foot-strike pattern (eg, postural alignment, hips ahead of feet in midstance, knees bent at impact, no heel striking). ${ }^{21}$ Runners who described themselves as Chi or Pose runners and had received formal training in either of these running styles were analyzed in a separate study because we did not want formal training in a particular running form to be a confounding variable.

Sixty runners from 3 groups were included in the data analyses: (1) runners who wore traditional shoes and had a rear-foot-strike pattern (TSR; $n=22$ ), (2) runners who wore minimalist shoes and had an anterior-foot-strike pattern (MSA; $n=21$ ), and (3) runners who wore minimalist shoes and had a rear-foot-strike pattern but self-reported that they had an anterior-foot-strike pattern (MSR; $\mathrm{n}=17$; Table 1 and Figure 1). Traditional shoes were defined as motion-control, stability, or cushioning shoes with a greater than $10-\mathrm{mm}$ drop from heel height to forefoot height. Minimalist shoes were defined as any shoes that were very flexible, contained minimal supportive features, and had a heel-to-forefoot drop of $4 \mathrm{~mm}$ or less per the specifications listed on the Web site of the respective shoe manufacturer. The principal investigator (D.L.G.) made the determination based on the manufacturer's specifications and his assessment of minimalist shoes that were folded easily in half and twisted along their longitudinal axes with minimal resistance to deformation. Data concerning shoe type and models were obtained for the minimalist shoe groups during the interview before data collection.

Exclusion criteria were a lower extremity injury or low back pain that limited lower extremity function for the 3 months preceding the study. Participants reported using the 


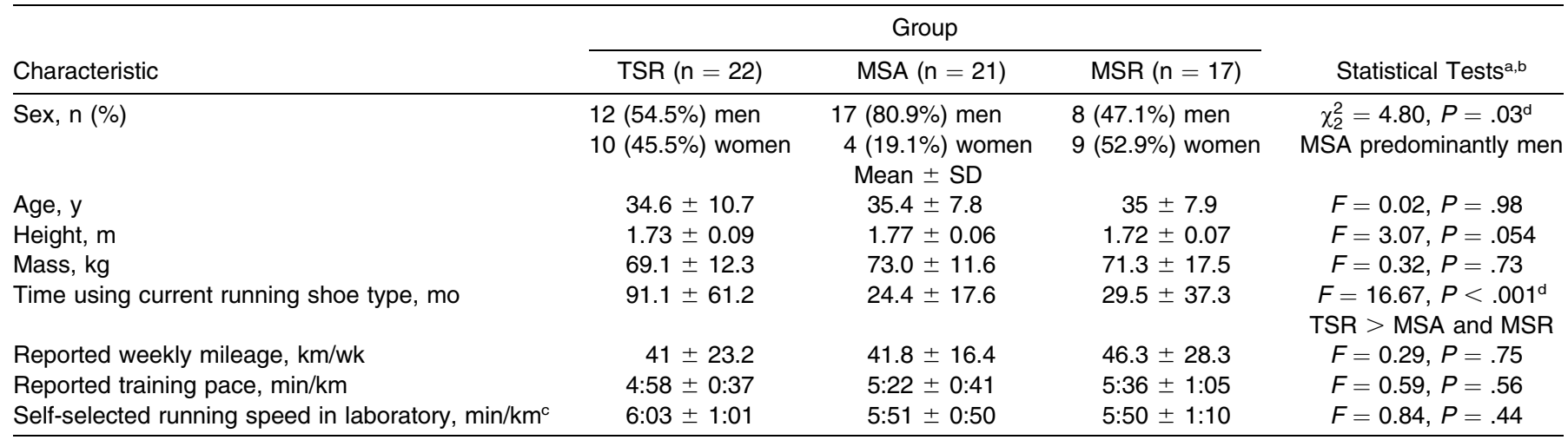

Abbreviations: MSA, runners wearing minimalist shoes and using an anterior-foot-strike pattern; MSR, runners wearing minimalist shoes and using a rear-foot-strike pattern; TSR, runners wearing traditional shoes and using a rear-foot-strike pattern.

a Chi-square analysis was conducted on sex proportions, and 1-way analyses of variance were conducted on other descriptive statistics variables to assess differences among groups.

b The degrees of freedom for the $F$ values are not reported because this output was unavailable to the authors after study completion.

${ }^{c}$ Reported training pace was faster than self-selected running speed in the laboratory $(t=11.39, P<.001)$.

d Indicates difference.

same shoe type for at least 6 months before this study. Runners in the minimalist-shoe groups had worn minimalist footwear for more than $50 \%$ of their weekly mileage for at least 6 months before inclusion in the study. Exclusion criteria were barefoot running, a history of lower extremity or lumbar surgery, or pregnancy in the 6 months before the study. All participants provided written informed consent, and the study was approved by the institutional review boards at the University of North Carolina at Chapel Hill and Womack Army Medical Center, Fort Bragg, North Carolina.

\section{Data Collection}

Data were collected during a single visit in which participants had 39 reflective markers affixed to their shoes, medial and lateral ankles, legs, medial and lateral knees, posterior thighs, greater trochanters, iliac crests, and sacrum in a fashion similar to an established marker set. ${ }^{22} \mathrm{We}$ instructed them to stand still on the treadmill for 1 second while we obtained a static calibration of the full marker set. Next, 14 markers were removed to allow for data collection during the running trials.

During data collection, we instructed participants to run for 5 minutes at a comfortable self-selected speed in their preferred running shoes. Reported training pace was used as a target speed. The principal investigator accelerated the treadmill gradually until the runner stated that he or she was comfortable with the pace. Participants were not able to view the speed display. The principal investigator did not insist participants run at their reported training paces. One attempt was performed in all cases. The first 4 minutes were used for participants to acclimate to the treadmill. ${ }^{23-25}$ Data collection consisted of five 3 -second trials during the final minute of running. ${ }^{26,27}$ To reduce measurement bias, participants were blinded to exactly when data were being collected.

Running was conducted on the right belt of a split-belt instrumented treadmill (model TM-06-B; Bertec Corp, Columbus, $\mathrm{OH}$ ) with force plates sampling data at 1200 $\mathrm{Hz}{ }^{25,28}$ Three-dimensional kinematic data were captured using an 8-camera Vicon Nexus MX40+ system (Vicon Motion Systems Ltd, Centennial, CO) sampling at 240 $\mathrm{Hz}^{28-30}$ A Sony Handycam (model HDR-CX150; Sony Corp, Park Ridge, NJ) sampling at $60 \mathrm{~Hz}$ was positioned perpendicularly to the treadmill to obtain lateral views of runners to confirm foot-strike patterns.

\section{Data Reduction}

Data processing and reduction were performed using a customized computer program package (MS3D 2010; Motionsoft Inc, Washington, DC). ${ }^{31}$ The data-smoothing methods and smoothing settings for ground reaction forces, free moment, and coordinates of center of pressure were selected after an analysis of the signal-to-noise ratios, frequency spectrums, and patterns of the signals. ${ }^{32}$ Additional details of the data-filtering settings were included in a previous report. ${ }^{21}$

An inverse-dynamics approach was used to calculate joint moments. Data were averaged across 5 strides for each participant and averaged with data from other runners in the same group. After the initial data processing, we calculated average joint angles, joint angular velocities, ground reaction forces, internal net joint moments, and net joint power files (force $\times$ velocity) from normalized individual trial data. Normalization was conducted on the first 5 rightstance phases captured from the five 3-second running periods. Force was normalized to body weight $(\mathrm{BW})(\times$ $\mathrm{BW}$ ). Joint moments were normalized to the product of body height $(\mathrm{BH})$ and $\mathrm{BW}(\times \mathrm{BH} \cdot \mathrm{BW})$. Joint powers were normalized to watts per the product of $\mathrm{BH}$ and $\mathrm{BW}(\times \mathrm{W} /$ $[\mathrm{BH} \cdot \mathrm{BW}])$. Work was normalized to joules per the product of $\mathrm{BH}$ and $\mathrm{BW}(\times \mathrm{J} /[\mathrm{BH} \cdot \mathrm{BW}])$. Loading rates and angular work variables were computed using nonnormalized time data.

Angular work was defined as $\mathrm{T} \times \theta$, where $\mathrm{T}$ is torque and $\theta$ is angular joint displacement, or $\mathrm{I} \times \alpha \times \theta$, where $\mathrm{I}$ is the mass moment of inertia of a segment, $\alpha$ is angular acceleration, and $\theta$ is angular joint displacement. Negative work was computed through the duration of the stance phase by integrating all periods of negative power. 

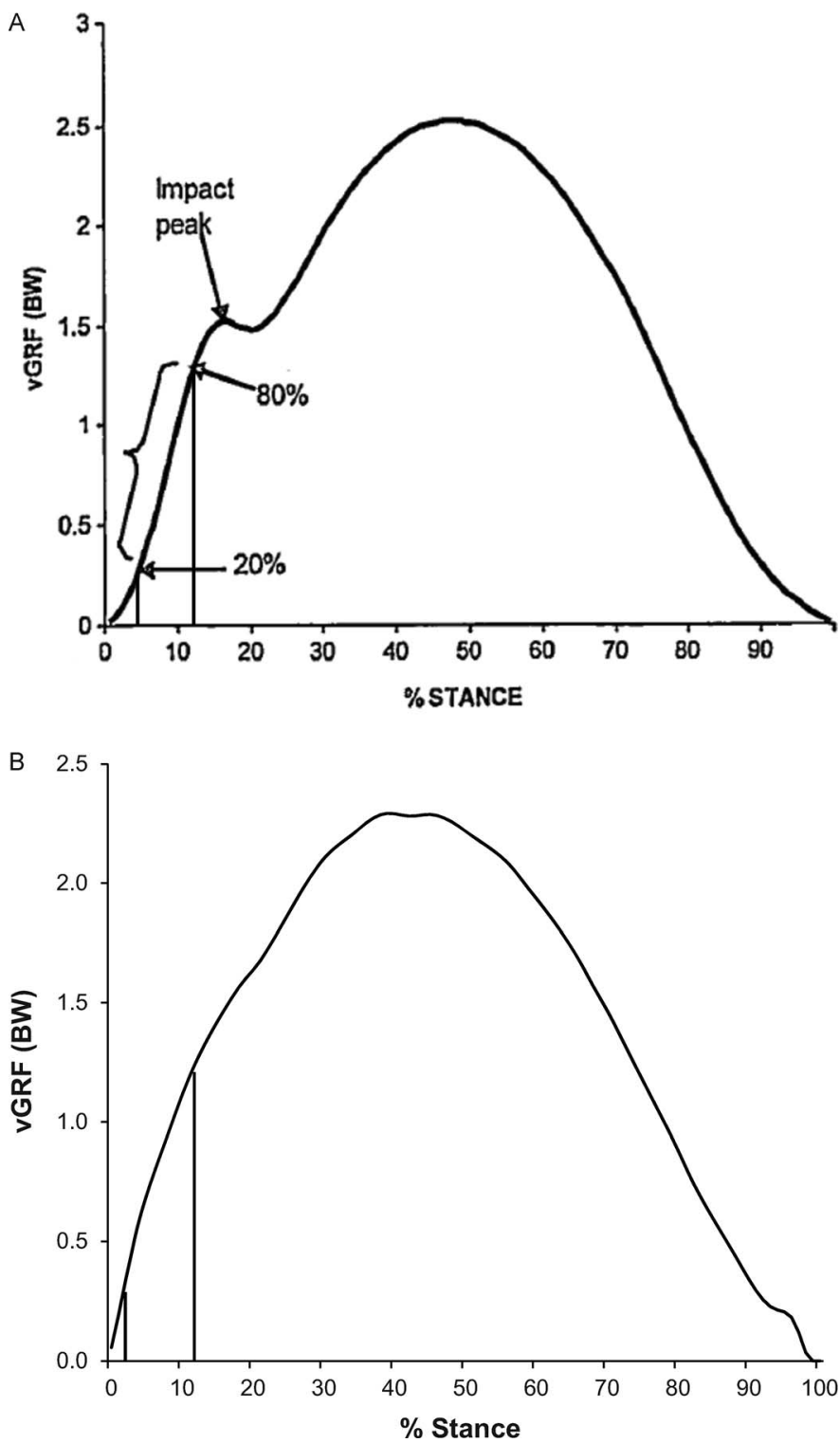

Figure 2. A, Average vertical ground reaction force (vGRF) loading rate is depicted as the slope of the line from $20 \%$ to $80 \%$ of the stance time to impact peak. The lines designate $3 \%$ to $12 \%$ stance phase. Adapted with permission from Lippincott Williams and Wilkins/Wolters/Kluwer Health: Medicine and Science in Sports and Exercise. Milner CE, Ferber R, Pollard CD, Hamill J, Davis IS. Biomechanical factors associated with tibial stress fracture in female runners. 2006;38(2):323-328. B, In the absence of an impact peak, the mean loading rate is depicted as the slope of the line from $3 \%$ to $12 \%$ of stance phase. Abbreviation: BW, body weight.

Negative work was calculated to determine how much kinetic energy was dampened at the ankle and knee joints. Concentric work (ie, the integral of positive power) was not compared in this analysis.

Vertical-loading rates were based on the relationship between nonnormalized time and normalized ground reaction force measured in units of BW. Average verticalloading rate was defined as the slope of the vertical ground reaction force curve from $20 \%$ to $80 \%$ of the stance time from initial contact to impact peak ${ }^{7,33}$ (Figure 2A) or, in the absence of an impact peak, from $3 \%$ to $12 \%$ of the stance phase (Figure 2B). Vertical ground reaction force data were extracted from the normalized force-plate data using custom MATLAB software (The MathWorks, Inc, Natick, MA). Initial contact was defined as the instant when vertical ground reaction force consistently measured more than $0 \mathrm{~N}$, and toe-off was defined as the instant when vertical ground reaction forces were no longer positive.

Additional variables obtained to help explain the clinical implications of the lower extremity work and vertical ground reaction force variables were running speed, ankle and knee angular excursion during stance (maximal minimal angle), step frequency, and maximal vertical ground reaction force during stance phase. When total joint excursion differed among groups, joint-excursion curves were investigated to ascertain where differences were located.

Foot-strike pattern was determined using the $60-\mathrm{Hz}$ video camera that provided a lateral view of each runner. This was used to confirm rear-foot-strike patterns for TSR or to place minimalist shoe runners into either the MSA or MSR group. Two physical therapists (D.L.G., M.T.G.) with more than 40 years of combined clinical experience separately evaluated the video of each runner. Foot-strike patterns were categorized into 2 groups: rear-foot-strike pattern and anterior-foot-strike (nonrear-foot-strike) pattern based on the location of initial foot contact relative to the ankle joint. When the physical therapists disagreed, the presence or absence of an impact peak in the vertical ground reaction force curve was used to determine rear-foot or anteriorfoot-strike pattern, respectively. Running with a rear-footstrike pattern is associated with the presence of impact peaks, whereas running with an anterior-foot-strike pattern may eliminate the presence of an impact peak. ${ }^{9,34}$

\section{Data Analysis}

We computed a priori power calculations using G*Power software (version 3.1.2; Heinrich-Heine-Universität Düsseldorf, Düsseldorf, Germany) for a medium effect size $\left(f^{2}=0.25\right)$, the $\alpha$ level was set at .05 for the primary variables of interest (AVLR, joint work variables), and the study was deemed to be adequately powered with an estimated sample size of 20 runners per group. Kinematic and kinetic sex differences have been observed in the sagittal plane, ${ }^{35,36}$ as well as in the frontal and transverse planes. ${ }^{36,37}$ Differences observed in kinematic and kinetic variables may have been affected by sex differences. Therefore, sex was selected as a covariate due to the differences in sex proportions noted among the groups of runners. We conducted univariate 1-way analyses of covariance on the biomechanical variables using selfselected running speed and sex as covariates in the analysis. The Tukey honestly significant difference test was used for pairwise comparisons when omnibus analyses of covariance were different.

Group mean age, height, mass, average weekly mileage, average training pace, and length of time using the particular type of running shoe were compared using 1way analyses of variance. Sex proportions among groups were compared using $\chi^{2}$ analysis. Reported training pace was compared with self-selected running speed on the treadmill using a paired-samples $t$ test.

The actual foot-strike pattern and reported foot-strike pattern from the descriptive data interview were compared among groups using $\chi^{2}$ analysis and $\kappa$ coefficients. We also 


\begin{tabular}{|c|c|c|c|c|}
\hline \multirow[b]{2}{*}{ Variable } & \multicolumn{3}{|c|}{ Group, Mean \pm SD } & \multirow[b]{2}{*}{ Statistical Tests ${ }^{a, b}$} \\
\hline & TSR & MSA & MSR & \\
\hline Vertical loading rate, $\mathrm{BW} / \mathrm{s}$ & $68.55 \pm 15.45$ & $54.48 \pm 30.90$ & $105.67 \pm 35.68$ & $\begin{array}{r}F=15.22, P<.001^{\mathrm{C}} \\
\mathrm{TSR}<\mathrm{MSR}, P<.001^{\mathrm{C}} \\
\mathrm{MSA}<\mathrm{MSR}, P<.001^{\mathrm{C}}\end{array}$ \\
\hline Ankle negative dorsiflexion work, $\mathrm{J} /(\mathrm{BH} \cdot \mathrm{BW})$ & $-0.004 \pm 0.008$ & $<-0.001 \pm 0.001$ & $<-0.001 \pm 0.001$ & $\begin{array}{r}F=3.21, P=.048^{\mathrm{c}} \\
\text { TSR }>\mathrm{MSA}, P=.03^{\mathrm{c}} \\
\text { TSR }>\mathrm{MSR}, P=.04^{\mathrm{c}}\end{array}$ \\
\hline Knee-extension negative work, $\mathrm{J} /(\mathrm{BH} \cdot \mathrm{BW})$ & $-0.332 \pm 0.111$ & $-0.161 \pm 0.133$ & $-0.227 \pm 0.138$ & $\begin{array}{r}F=8.91, P<.001^{\mathrm{c}} \\
\text { TSR }>\mathrm{MSA}, P<.001^{\mathrm{c}} \\
\mathrm{TSR}>\mathrm{MSR}, P=.01^{\mathrm{c}}\end{array}$ \\
\hline Ankle excursion, ${ }^{\circ}$ & $19.84 \pm 3.26$ & $24.10 \pm 7.22$ & $21.90 \pm 3.73$ & $\begin{aligned} F=4.71, P & =.01^{\mathrm{c}} \\
\mathrm{TSR}<\mathrm{MSA}, P & =.008^{\mathrm{c}}\end{aligned}$ \\
\hline
\end{tabular}

Abbreviations: $\mathrm{BH}$, body height; $\mathrm{BW}$, body weight; MSA, runners wearing minimalist shoes and using an anterior-foot-strike pattern; MSR, runners wearing minimalist shoes and using a rear-foot-strike pattern; TSR, runners wearing traditional shoes and using a rear-foot-strike pattern.

a One-way univariate analyses of covariance were conducted on all variables to assess differences among groups. Self-selected running speed and sex were used as covariates.

b The degrees of freedom for the $F$ values are not reported because this output was unavailable to the authors after study completion.

${ }^{c}$ Indicates difference.

calculated $\kappa$ coefficients for foot-strike category between physical therapists. We used SPSS software (version 21; IBM Corporation, Armonk, NY) to analyze these data.

\section{RESULTS}

In the TSR group, 12 of $22(54.5 \%)$ of the runners were men (Table 1). Minimalist shoe wearers from the MSA and MSR groups were predominantly men (25 of 38, 65.8\%). The analysis of sex proportions yielded a difference $\left(\chi_{2}^{2}=\right.$ $4.80, P=.03)$, with a greater proportion of men in the MSA group (17 of $21,80.9 \%$ ). Age, height, and mass did not differ among groups (Table 1). The TSR group reported using their running styles longer (91.1 months) than the MSA (24.4 months) and MSR (29.5 months) groups $(F=$ 16.67, $P<.001$; Table 1). ${ }^{\mathrm{a}}$ Reported weekly running distance and reported training pace did not differ among groups (Table 1).

\section{Foot-Strike Patterns and Loading Rates}

Only 41 runners $(68.3 \%, \kappa=0.42, P<.001)$ accurately reported their foot-strike patterns before data collection. Video-assessed foot-strike pattern differed from the reported pattern $\left(\chi_{1}^{2}=16.15, P<.001\right)$. The percentage agreement among traditional shoe wearers who thought they had a rearfoot-strike pattern was $90.9 \%$ (20 of 22 ). Two runners wearing traditional shoes reported using an anterior-footstrike pattern, but all 22 runners wearing traditional shoes demonstrated a rear-foot-strike pattern. The percentage agreement in the minimalist shoe group who thought they

\footnotetext{
${ }^{\text {a }}$ The degrees of freedom for the $F$ and $t$ values are not reported because this output was unavailable to the authors after study completion.
}

had an anterior-foot-strike pattern was $57.5 \%$ (23 of 40), whereas $42.5 \%$ (17 of 40 ) demonstrated a rear-foot-strike pattern. Percentage agreement between the 2 investigators who evaluated slow-motion videos for foot-strike pattern was $98.3 \%(\kappa=0.96, P<.001)$, with disagreement on only 1 participant. On our review of the kinetic data, this runner did not demonstrate an impact peak on his vertical ground reaction force curve. ${ }^{7,31}$ Slow-motion animation of the runner demonstrated that the point of application of the resultant ground reaction force vector (center of pressure) was located anteriorly to the ankle-joint center, which was consistent with an anterior-foot-strike pattern. Therefore, the participant was included in the MSA group.

The MSR group demonstrated greater AVLR (105.67 \pm $35.68 \mathrm{BW} / \mathrm{s})$ than the TSR $(68.55 \pm 15.45 \mathrm{BW} / \mathrm{s} ; P<$ $.001)$ and MSA $(54.48 \pm 30.90 \mathrm{BW} / \mathrm{s} ; P<.001)$ groups (Table 2 and Figure 2B). No differences were detected among groups for maximal vertical ground reaction force $(F=1.67, P=.20)$.

\section{Work Variables}

The TSR runners $(-0.004 \pm 0.008 \mathrm{~J} /[\mathrm{BH} \times \mathrm{BW}])$ demonstrated greater ankle-dorsiflexion negative work $(\mathrm{ADNW})$ than MSA $(<-0.001 \pm 0.001 \mathrm{~J} /[\mathrm{BH} \times \mathrm{BW}]$; $P=.03)$ and $\operatorname{MSR}(<-0.001 \pm 0.001 \mathrm{~J} /[\mathrm{BH} \times \mathrm{BW}] ; P=$ $.04)$ runners (Table 2$)$. The TSR runners also demonstrated greater knee-extension negative work (KENW) $(-0.332 \pm$ $0.11 \mathrm{~J} /[\mathrm{BH} \times \mathrm{BW}])$ than MSA $(-0.161 \pm 0.133 \mathrm{~J} /[\mathrm{BH} \times$ $\mathrm{BW}] ; P<.001)$ and $\operatorname{MSR}(-0.227 \pm 0.138 \mathrm{~J} /[\mathrm{BH} \times \mathrm{BW}]$; $P=.01)$ runners. The MSA runners $(-0.523 \pm 0.227 \mathrm{~J} /$ $[\mathrm{BH} \times \mathrm{BW}] ; P<.001)$ and MSR runners $(-0.429 \pm 0.195$ $\mathrm{J} /[\mathrm{BH} \times \mathrm{BW}] ; P=.01)$ demonstrated greater ankle- 


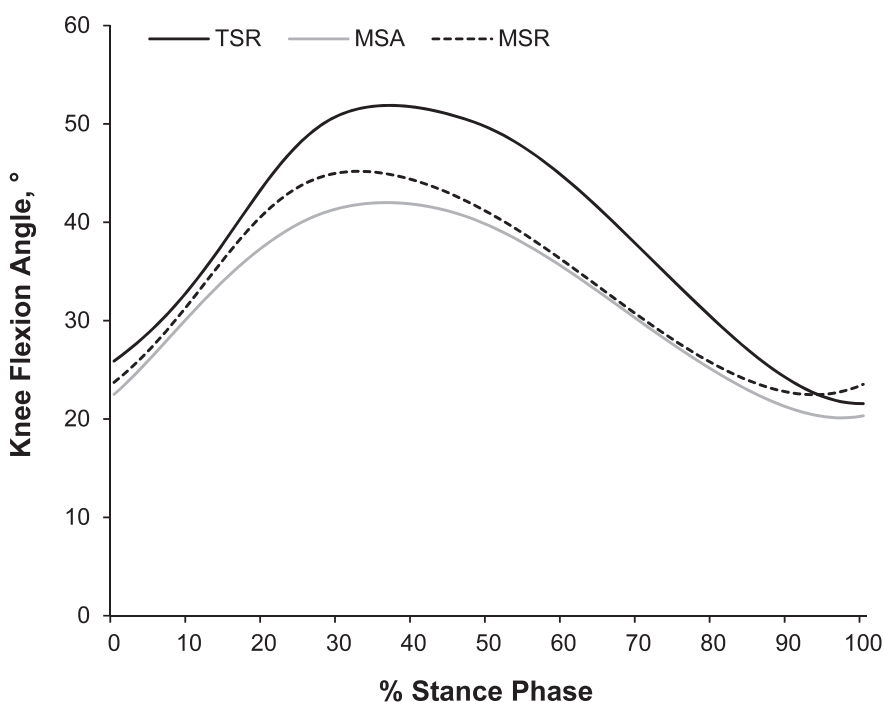

Figure 3. Knee excursion during stance phase. Abbreviations: MSA, runners wearing minimalist shoes and using an anterior-footstrike pattern; MSR, runners wearing minimalist shoes and using a rear-foot-strike pattern; TSR, runners wearing traditional shoes and using a rear-foot-strike pattern.

plantar-flexion negative work (APNW) than TSR runners $(-0.315 \pm 0.131 \mathrm{~J} /[\mathrm{BH} \times \mathrm{BW}])$.

Self-selected running speed was not different among the 3 groups $(F=0.84, P=.44)$; however, reported training pace was faster than self-selected running speed on the laboratory treadmill $(t=11.39, P<.001)$. The average reported training pace was approximately 3.0 to $3.2 \mathrm{~m} / \mathrm{s}$ $(4: 58$ to $5: 36 \mathrm{~min} / \mathrm{km})$ in all 3 groups. Actual self-selected running speed in the laboratory ranged from 2.7 to $2.9 \mathrm{~m} / \mathrm{s}$ (5:50 to $6: 03 \mathrm{~min} / \mathrm{km})$ for each group. Step frequency differed among groups $(F=3.27, P=.02$; Table 2$)$.

The TSR group demonstrated less ankle excursion during stance phase $\left(19.84^{\circ} \pm 3.26^{\circ}\right)$ than the MSA group $\left(24.10^{\circ} \pm\right.$ $\left.7.22^{\circ}, P=.008\right)$. The most obvious difference occurred at initial contact (Figure 3), with the TSR group contacting the ground with the ankle in more dorsiflexion than the other

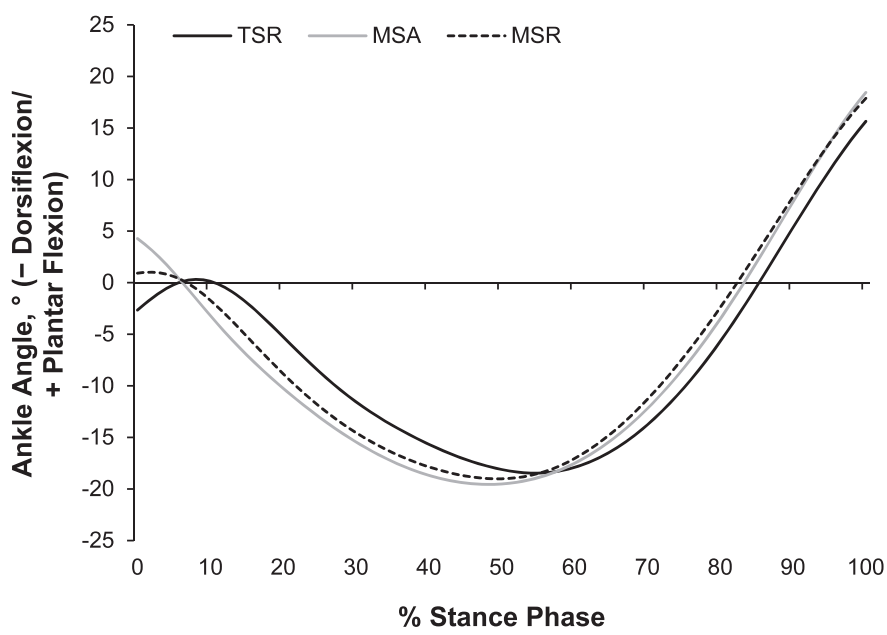

Figure 4. Ankle excursion during stance phase. Abbreviations: MSA, runners wearing minimalist shoes and using an anterior-footstrike pattern; MSR, runners wearing minimalist shoes and using a rear-foot-strike pattern; TSR, runners wearing traditional shoes and using a rear-foot-strike pattern.

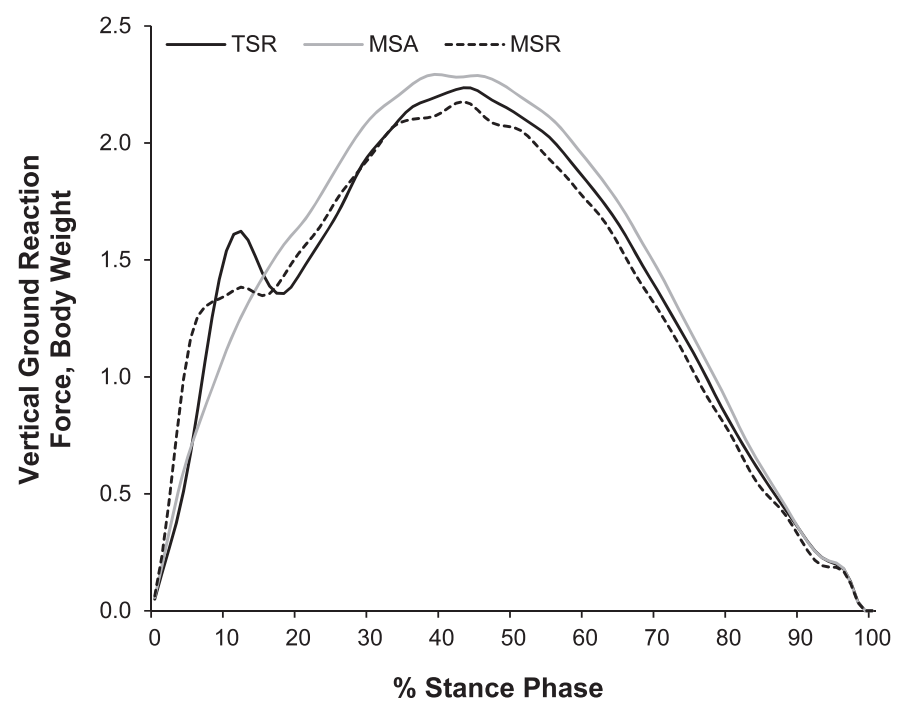

Figure 5. Vertical ground reaction force curves for runners wearing traditional shoes and using a rear-foot-strike pattern (TSR), wearing minimalist shoes and using an anterior-foot-strike pattern (MSA), and wearing minimalist shoes and using a rear-footstrike pattern (MSR).

groups. Ankle excursion for the MSR group did not differ from the other 2 groups. The TSR group demonstrated greater total knee excursion during stance phase $\left(25.88^{\circ} \pm 5.18^{\circ}\right)$ than the MSA group $\operatorname{did}\left(19.87^{\circ} \pm 5.43^{\circ}, P=.001\right)$. The major difference in angle occurred during midstance (Figure 4$)$.

\section{DISCUSSION}

\section{Foot-Strike Patterns and Loading Rates}

The accuracy of self-reported foot-strike pattern was poor for runners who wore minimalist running shoes. After video assessment, we identified a cohort of 17 runners who wore minimalist shoes for a minimum of 6 months, reported running $46.3 \mathrm{~km} / \mathrm{wk}$, and demonstrated a rear-foot-strike pattern with vertical-loading rates that have been associated with injury in previous studies. ${ }^{5-7,38-42}$ At the time of study conception, the prevailing thinking was that runners who wore minimalist running shoes automatically would transition to using an anterior-foot-strike pattern. ${ }^{17}$ Minimalist footwear is marketed to imply that runners will alter their running forms and adopt an anterior-foot-strike pattern when they begin using the product. However, researchers ${ }^{20}$ have reported that 8 of $16(50 \%)$ runners recently introduced to minimalist shoes still used a rearfoot-strike pattern after 2 weeks of accommodation. Our findings support the concept that runners who wear minimalist footwear do not transition automatically to an anterior-foot-strike pattern. Specifically, the MSR runners reported wearing minimalist shoes for a mean of 29.5 months and reported no history of injury in the 3 months before enrolling in the study. Both the existence of the MSR group and the fact that these runners demonstrated AVLR greater than previously demonstrated by runners with a history of injury surprised us.

Based on the findings of Milner et al, ${ }^{7}$ Pohl et al, ${ }^{6}$ and Davis et $\mathrm{al}^{5,38}$ the increased average vertical ground reaction force loading rates in the MSR group (105.67 BW/ s) may place this group at higher risk for injury (Figure 5). 
These authors used similar methods for calculating AVLR: the slope of the vertical ground reaction force curve from $20 \%$ to $80 \%$ of the time to impact peak. They gave no descriptions for calculating AVLR in the absence of an impact peak. Researchers ${ }^{5,38,42}$ have observed AVLR between 60 and $70 \mathrm{BW} / \mathrm{s}$ in healthy runners, which is consistent with the MSA and TSR groups. The AVLR greater than $70 \mathrm{BW} / \mathrm{s}$ have been associated with tibial and metatarsal stress fractures, ${ }^{8,42}$ instantaneous vertical ground reaction force loading rates greater than $100 \mathrm{BW} /$ s have been associated with plantar fasciitis, ${ }^{6}$ and AVLR greater than $72 \mathrm{BW} / \mathrm{s}$ have been linked to patellofemoral pain syndrome. ${ }^{5,38}$ Runners with histories of these injuries, therefore, should be cautioned against wearing minimalist shoes if they cannot adopt an anterior-foot-strike pattern.

These results suggest that the increased AVLR observed in MSR runners may be a combination of a rear-foot-strike pattern and the lack of cushioning in the rear foot of their shoes. The fact that we did not observe a difference in average AVLR between the TSR and MSA groups suggests that the observed differences are not merely due to footstrike pattern. The greater AVLR of the MSR group may be problematic because these runners also were wearing minimalist shoes, which reduce plantar contact area and increase calcaneal contact pressure. ${ }^{43,44}$

The vertical ground reaction force curves of all MSR and TSR runners in this study contained impact peaks. No MSA vertical ground reaction force curves contained impact peaks. These findings support data reported by Lieberman et al. ${ }^{9}$

\section{Work Variables}

Runners in the MSA group demonstrated less ADNW and KENW than the TSR group. These results may have important clinical implications for runners who want to avoid recurrence or promote resolution of anterior chronic exertional compartment syndrome or knee-joint injuries, respectively. The MSA runners also demonstrated greater APNW, perhaps making this combination of running shoe and foot-strike pattern undesirable for runners with current or previous Achilles tendinopathy injuries. The pattern of negative ankle work in the first $10 \%$ of the stance phase is determined primarily by the location of the external vertical ground reaction force vector. ${ }^{45}$ We observed 2 distinct patterns in the TSR and MSA groups depending on whether the vertical ground reaction force vector was located anterior or posterior to the ankle-joint axis. A dorsiflexed ankle at impact places the vertical ground reaction force vector posteriorly to the ankle joint. A plantar-flexed ankle joint at impact places the ground reaction force vector anteriorly to the ankle joint and requires additional APNW. The MSA runners may have attenuated the vertical ground reaction forces using ankle-joint motion because they demonstrated the greatest amount of ankle-joint excursion.

We are unaware of "safe" and "potentially injurious" levels of ankle- and knee-joint negative work values. Further research is needed to compare ADNW between healthy runners who have a rear-foot-strike pattern and runners who have a history of anterior chronic exertional compartment syndrome and a rear-foot-striker pattern during treadmill and overground running. Researchers should quantify APNW for healthy individuals running barefoot or in minimalist shoes and for runners with a history of chronic Achilles tendinopathy. Further investigation is also needed to examine the association of KENW in runners with and without a history of pathologic knee conditions.

The TSR runners demonstrated greater ADNW and KENW than the other 2 groups. Greater ADNW may be related more to the additional posterior flare present on traditional running shoes and to the rear-foot-strike pattern. ${ }^{46}$ Knee-joint angles were similar at initial contact (Figure 4), but the orientation of the ankle at impact and the additional rear-foot cushioning in the traditional shoes placed the vertical ground reaction force vector of the TSR group posteriorly to the knee at initial contact. A ground reaction force vector oriented more posteriorly to the knee creates an external knee-flexion moment that must be countered by an internal knee-extension moment. Greater knee excursion in the TSR group contributed to the greater KENW and attenuation of the vertical ground reaction force through the knee joint. Again, these findings were more associated with shoe type than with foot-strike pattern. Greater KENW may indicate greater force generation in the knee-extensor muscle group or greater angular velocity in the knee joint. Increased knee-extension force may lead to greater compressive forces at the tibiofemoral and patellofemoral joints. Increased contact pressure at these joints may lead to the degradation of articular cartilage and is consistent with the increased prevalence of knee injuries that are self-reported by runners who wear traditional shoes and who also demonstrate a rear-foot-strike pattern. ${ }^{2,47}$ The MSA runners, however, used increased ankle excursion and increased APNW to reduce the vertical ground reaction force loading rate. Arendse et $\mathrm{al}^{13}$ also observed reduced KENW and greater APNW in a group of Pose runners who used a forefoot-strike pattern compared with runners who used either a midfoot or rear-foot-strike pattern.

The MSR runners demonstrated less ADNW than the TSR runners and less APNW than the MSA runners. Biomechanically, a simplified explanation for this location of the ground reaction force is that MSR runners contacted the ground in less dorsiflexion than the TSR runners (Figure 3 ). This contact position likely placed the ground reaction force vector closer to the ankle-joint center. Traditional running shoes with greater heel thickness beneath and posterior to the heel may increase the moment arm for the ground reaction force at the ankle joint. ${ }^{45}$ The MSR runners who contacted the ground in less dorsiflexion than TSR runners, coupled with reduced shoe-heel thickness, may have reduced the plantar-flexion moment arm from the ground reaction force, resulting in the reduced negative dorsiflexion work for this group. Whereas this method of analysis is associated with some error because the vertical ground reaction force imposes moment on the ankle and the ankle reaction force imposes moment on the knee, the reduced APNW in the MSR group compared with the MSA group was likely due to foot-strike pattern because shoe type was similar between these groups.

\section{Study Limitations}

Instructing runners who are accustomed to overground running to run on a treadmill can influence kinematic and kinetic gait characteristics. ${ }^{48,49}$ Repeating this study over 
ground with greater numbers of male and female runners would be beneficial to validate these results.

We affixed reflective markers over the posterior heel, lateral heel, and fifth metatarsal head of runners with a variety of shoes. The varying thickness of traditional and minimalist shoes coupled with the movement of the foot inside the shoe may have contributed to error in our data. Our 2-dimensional method of characterizing foot-strike pattern is a limitation of this study, but we believe the investigation by Altman and Davis ${ }^{50}$ supports our methods. These authors stated that 2-dimensional slow-motion video data from a standard video camera might lead to an even greater ability to determine foot-strike pattern than the footstrike angle method. ${ }^{50}$

\section{CONCLUSIONS}

Accuracy of self-reported foot-strike pattern was poor for runners who wore minimalist running shoes. We identified a cohort of runners who wore minimalist shoes for a minimum of 6 months and self-reported an anteriorfoot-strike pattern; however, more than $40 \%$ actually demonstrated a rear-foot-strike pattern and were at risk for potentially injurious rates of ground reaction force loading. We also observed that runners who used a rearfoot-strike pattern in traditional shoes demonstrated more overall knee excursion, greater $\mathrm{KENW}$, and greater ADNW than runners wearing minimalist shoes, regardless of foot-strike pattern.

\section{REFERENCES}

1. 2012 State of the sport part II: running industry report. Running USA Web site. http://www.runningusa.org/2012-state-of-sport-part-2? returnTo=annual-reports. Accessed May 5, 2014.

2. van Gent RN, Siem D, van Middelkoop M, van Os AG, BiermaZeinstra SM, Koes BW. Incidence and determinants of lower extremity running injuries in long distance runners: a systematic review. Br J Sports Med. 2007;41(8):469-480.

3. Taunton JE, Ryan MB, Clement DB, McKenzie DC, Lloyd-Smith DR, Zumbo BD. A prospective study of running injuries: the Vancouver Sun Run "In Training" clinics. Br J Sports Med. 2003; 37(3):239-244.

4. Milner CE, Davis IS, Hamill J. Free moment as a predictor of tibial stress fracture in distance runners. J Biomech. 2006;39(15):2819 2825.

5. Davis I, Bowser B, Hamill J. Vertical impact loading in runners with a history of patellofemoral pain syndrome. Paper presented at: The 57th Annual Meeting of the American College of Sports Medicine; June 2-5, 2010; Baltimore, MD.

6. Pohl MB, Hamill J, Davis IS. Biomechanical and anatomic factors associated with a history of plantar fasciitis in female runners. Clin $J$ Sport Med. 2009;19(5):372-376.

7. Milner CE, Ferber R, Pollard CD, Hamill J, Davis IS. Biomechanical factors associated with tibial stress fracture in female runners. Med Sci Sports Exerc. 2006;38(2):323-328.

8. Zifchock RA, Davis I, Hamill J. Kinetic asymmetry in female runners with and without retrospective tibial stress fractures. $J$ Biomech. 2006;39(15):2792-2797.

9. Lieberman DE, Venkadesan M, Werbel WA, et al. Foot strike patterns and collision forces in habitually barefoot versus shod runners. Nature. 2010;463(7280):531-535.

10. Hasegawa H, Yamauchi T, Kraemer WJ. Foot strike patterns of runners at the $15-\mathrm{km}$ point during an elite-level half marathon. $J$ Strength Cond Res. 2007;21(3):888-893.
11. Larson P, Higgins E, Kaminski J, et al. Foot strike patterns of recreational and sub-elite runners in a long-distance road race. $J$ Sports Sci. 2011;29(15):1665-1673.

12. Hatala KG, Dingwall HL, Wunderlich RE, Richmond BG. Variation in foot strike patterns during running among habitually barefoot populations. PLoS One. 2013;8(1):e52548.

13. Arendse RE, Noakes TD, Azevedo LB, Romanov N, Schwellnus MP, Fletcher G. Reduced eccentric loading of the knee with the pose running method. Med Sci Sports Exerc. 2004;36(2):272-277.

14. Heiderscheit BC, Chumanov ES, Michalski MP, Wille CM, Ryan MB. Effects of step rate manipulation on joint mechanics during running. Med Sci Sports Exerc. 2011;43(2):296-302.

15. De Wit B, De Clercq D, Aerts P. Biomechanical analysis of the stance phase during barefoot and shod running. J Biomech. 2000; 33(3):269-278.

16. Dixon SJ, Collop AC, Batt ME. Compensatory adjustments in lower extremity kinematics in response to a reduced cushioning of the impact interface in heel-toe running. Sports Eng. 2005;8(1):47-55.

17. Squadrone R, Gallozzi C. Biomechanical and physiological comparison of barefoot and two shod conditions in experienced barefoot runners. J Sports Med Phys Fitness. 2009;49(1):6-13.

18. Divert C, Mornieux G, Baur H, Mayer F, Belli A. Mechanical comparison of barefoot and shod running. Int J Sports Med. 2005; 26(7):593-598.

19. Divert C, Mornieux G, Freychat P, Baly L, Mayer F, Belli A. Barefoot-shod running differences: shoe or mass effect? Int J Sports Med. 2008;29(6):512-518.

20. McCarthy C, Porcari JP, Kernozek T, Willson J, Foster C, Anders M. Like barefoot, only better? American Council on Exercise (ACE) Web site. https://www.acefitness.org/certifiednewsarticle/1641/likebarefoot-only-better/. Accessed May 6, 2014.

21. Goss DL, Gross MT. A comparison of negative joint work and vertical ground reaction force loading rates in Chi runners and rear footstriking runners. J Orthop Sports Phys Ther. 2013;43(10):685-692.

22. Lewek MD, Osborn AJ, Wutzke CJ. The influence of mechanically and physiologically imposed stiff-knee gait patterns on the energy cost of walking. Arch Phys Med Rehabil. 2012;93(1):123-128.

23. Diss CE. The reliability of kinetic and kinematic variables used to analyse normal running gait. Gait Posture. 2001;14(2):98-103.

24. Fellin RE, Davis IS. Comparison of warm-up periods for treadmill running. Paper presented at: 33rd Annual Meeting of the American Society of Biomechanics; August 26-29, 2009; State College, PA.

25. Karamanidis K, Arampatzis A, Bruggemann GP. Reproducibility of electromyography and ground reaction force during various running techniques. Gait Posture. 2004;19(2):115-123.

26. Belli A, Lacour JR, Komi PV, Candau R, Denis C. Mechanical step variability during treadmill running. Eur J Appl Physiol Occup Physiol. 1995;70(6):510-517.

27. Craib M, Caruso C, Clifton R, Burleson C, Mitchell V, Morgan D. Daily variation in step length of trained male runners. Int $J$ Sports Med. 1994;15(2):80-83.

28. McCrory JL, Martin DF, Lowery RB, et al. Etiologic factors associated with Achilles tendinitis in runners. Med Sci Sports Exerc. 1999;31(10):1374-1381.

29. Bushnell T, Hunter I. Differences in technique between sprinters and distance runners at equal and maximal speeds. Sports Biomech. 2007; 6(3):261-268.

30. McClay I, Manal K. A comparison of three-dimensional lower extremity kinematics during running between excessive pronators and normals. Clin Biomech (Bristol, Avon). 1998;13(3):195-203.

31. Yu B, Lin CF, Garrett WE. Lower extremity biomechanics during the landing of a stop-jump task. Clin Biomech (Bristol, Avon). 2006; 21(3):297-305.

32. Yu B. Determination of the optimum cutoff frequency in the digital filter data smoothing procedure. J Biomech. 1989;22(10):988. 
33. Crowell HP, Milner CE, Hamill J, Davis IS. Reducing impact loading during running with the use of real-time visual feedback. $J$ Orthop Sports Phys Ther. 2010;40(4):206-213.

34. Daoud AI, Geissler GJ, Wang F, Saretsky J, Daoud YA, Lieberman DE. Foot strike and injury rates in endurance runners: a retrospective study. Med Sci Sports Exerc. 2012;44(7):1325-1334.

35. James CR, Sizer PS, Starch DW, Lockhart TE, Slauterbeck J. Gender differences among sagittal plane knee kinematic and ground reaction force characteristics during a rapid sprint and cut maneuver. Res $Q$ Exerc Sport. 2004;75(1):31-38.

36. Barrett R, Noordegraaf MV, Morrison S. Gender differences in the variability of lower extremity kinematics during treadmill locomotion. J Mot Behav. 2008;40(1):62-70.

37. Ferber R, Davis IM, Williams DS III. Gender differences in lower extremity mechanics during running. Clin Biomech (Bristol, Avon). 2003;18(4):350-357.

38. Davis I, Bowser B, Mullineaux D. Do impacts cause running injuries? A prospective study. Paper presented at: 34th Annual Meeting of the American Society of Biomechanics; August 18-21, 2010; Providence, RI.

39. Davis I, Milner C, Hamill J. Does increased loading during running lead to tibial stress fractures? A prospective study. Med Sci Sports Exerc. 2004;36(5):S58.

40. Noehren B, Davis I, Hamill J. ASB clinical biomechanics award winner 2006 prospective study of the biomechanical factors associated with iliotibial band syndrome. Clin Biomech (Bristol, Avon). 2007;22(9):951-956.

41. Pohl MB, Mullineaux DR, Milner CE, Hamill J, Davis IS. Biomechanical predictors of retrospective tibial stress fractures in runners. J Biomech. 2008;41(6):1160-1165.
42. Zadpoor AA, Nikooyan AA. The relationship between lowerextremity stress fractures and the ground reaction force: a systematic review. Clin Biomech (Bristol, Avon). 2011;26(1):2328.

43. Queen RM, Abbey AN, Wiegerinck JI, Yoder JC, Nunley JA. Effect of shoe type on plantar pressure: a gender comparison. Gait Posture. 2010;31(1):18-22.

44. Molloy JM, Christie DS, Teyhen DS, et al. Effect of running shoe type on the distribution and magnitude of plantar pressures in individuals with low- or high-arched feet. $J$ Am Podiatr Med Assoc. 2009;99(4):330-338.

45. Braunstein B, Arampatzis A, Eysel P, Brüggemann GP. Footwear affects the gearing at the ankle and knee joints during running. $J$ Biomech. 2010;43(11):2120-2125.

46. Gross MT, Yu B, Queen RM. Posterior heel flare and chronic exertional anterior compartment syndrome: a case study. Orthop Phys Ther Pract. 2005;17(4):8-13.

47. Goss DL, Gross MT. Relationships among self-reported shoe type, footstrike pattern, and injury incidence. US Army Med Dep J. 2012; Oct-Dec:25-30.

48. Schache AG, Blanch PD, Rath DA, Wrigley TV, Starr R, Bennell KL. A comparison of overground and treadmill running for measuring the three-dimensional kinematics of the lumbo-pelvichip complex. Clin Biomech (Bristol, Avon). 2001;16(8):667-680.

49. Wank V, Frick U, Schmidtbleicher D. Kinematics and electromyography of lower limb muscles in overground and treadmill running. Int J Sports Med. 1998;19(7):455-461.

50. Altman AR, Davis IS. A kinematic method for footstrike pattern detection in barefoot and shod runners. Gait Posture. 2012;35(2): 298-300.

Address correspondence to Donald L. Goss, PhD, PT, OCS, ATC, US Military-Baylor University Sports Medicine Doctoral Program, Keller Army Community Hospital, Bldg900 Washington Rd, West Point, NY 10996. Address e-mail to Donald_Goss@baylor.edu. 